\title{
Suitability Analysis of 17 Probiotic Type Strains of Lactic Acid Bacteria as Starter for Kimchi Fermentation
}

\author{
Hee Seo ${ }^{1,+}$, Jae-Han Bae ${ }^{1,+}$, Gayun Kim ${ }^{1}$, Seul-Ah Kim ${ }^{1}$, Byung Hee Ryu ${ }^{2}$ and Nam Soo Han ${ }^{1, *}$ \\ 1 Brain Korea 21 Center for Bio-Health Industry, Department of Food Science and Biotechnology, \\ Cheongju 28644, Korea; gmldi873@naver.com (H.S.); wassup74@hanmail.net (J.-H.B.); \\ lisugar@naver.com (G.K.); ksaha1004@naver.com (S.-A.K.) \\ 2 Fresh Food Research Division, Food BU, Daesang Corporation Research Institute, Icheon 17384, Korea; \\ ryubh@daesang.com \\ * Correspondence: namsoo@cbnu.ac.kr; Tel.: +82-43-261-2567 \\ $+\quad$ These authors contributed equally to the work.
}

Citation: Seo, H.; Bae, J.-H.; Kim, G.; Kim, S.-A.; Ryu, B.H.; Han, N.S. Suitability Analysis of 17 Probiotic Type Strains of Lactic Acid Bacteria as Starter for Kimchi Fermentation. Foods 2021, 10, 1435. https:// doi.org/10.3390/foods10061435

Academic Editors: Hae Choon Chang and Do-Won Jeong

Received: 13 May 2021

Accepted: 16 June 2021

Published: 21 June 2021

Publisher's Note: MDPI stays neutral with regard to jurisdictional claims in published maps and institutional affiliations.

Copyright: (c) 2021 by the authors. Licensee MDPI, Basel, Switzerland. This article is an open access article distributed under the terms and conditions of the Creative Commons Attribution (CC BY) license (https:/ / creativecommons.org/licenses/by/ $4.0 /)$.
Abstract: The use of probiotic starters can improve the sensory and health-promoting properties of fermented foods. This study aimed to evaluate the suitability of probiotic lactic acid bacteria (LAB) as a starter for kimchi fermentation. Seventeen probiotic type strains were tested for their growth rates, volatile aroma compounds, metabolites, and sensory characteristics of kimchi, and their characteristics were compared to those of Leuconostoc (Le.) mesenteroides DRC 1506, a commercial kimchi starter. Among the tested strains, Limosilactobacillus fermentum, Limosilactobacillus reuteri, Lacticaseibacillus rhamnosus, Lacticaseibacillus paracasei, and Ligilactobacillus salivarius exhibited high or moderate growth rates in simulated kimchi juice (SKJ) at $37^{\circ} \mathrm{C}$ and $15^{\circ} \mathrm{C}$. When these five strains were inoculated in kimchi and metabolite profiles were analyzed during fermentation using GC/MS and ${ }^{1} \mathrm{H}-\mathrm{NMR}$, data from the principal component analysis (PCA) showed that L. fermentum and $L$. reuteri were highly correlated with Le. mesenteroides in concentrations of sugar, mannitol, lactate, acetate, and total volatile compounds. Sensory test results also indicated that these three strains showed similar sensory preferences. In conclusion, L. fermentum and L. reuteri can be considered potential candidates as probiotic starters or cocultures to develop health-promoting kimchi products.

Keywords: kimchi; starter; probiotics; health promotion; Limosilactobacillus fermentum; Limosilactobacillus reuteri

\section{Introduction}

Kimchi is a traditional Korean fermented vegetable made by fermenting salted cabbage, radish, and cucumber with various spices, including red pepper powder, garlic, ginger, and other ingredients [1]. Natural fermentation with unsterilized raw materials leads to the growth of various microorganisms, including lactic acid bacteria (LAB), resulting in inconsistent quality of kimchi, which may hamper the commercial production of high-quality products [2,3]. The use of starter cultures in the manufacture of kimchi has been considered an alternative to solve these problems [4]. Applying a starter culture to kimchi has several advantages, such as uniform quality, enhanced sensory characteristics, extended shelf-life, and functional properties of the kimchi product [5,6]. Leuconostoc spp. are the dominant species present in the early phase of kimchi fermentation at low temperatures; Le. mesenteroides and Le. citreum have been used as industrial starters since the early 2000s [7,8]. However, despite their excellent role as starters, they are not considered as health-promoting probiotics because of their absence of resistance to acid and bile salt and low colonization capacity in the large intestine [9]. Thereby, in order to manufacture health-promoting kimchi products, the development of a probiotic starter that can be used as an alternative of Leuconostoc spp. is required.

$\mathrm{LAB}$ are present in traditional fermented foods as major starter cultures and are commonly used as health-promoting probiotics. A report by the World Health Organization 
(WHO) defined probiotics as "live microorganisms which when administered in adequate amounts confer a health benefit on the host $[10,11]$ ". Fermented foods can be used as delivery vehicles for probiotics $[12,13]$. A previous study reported that consumption of not only pure probiotics but also foods fermented using the same probiotic resulted in equal levels of functionality in piglets; administration of Propionibacterium freudenreichii in the form of bacteria cells and fermented cheese increased the population of Propionibacteria and the levels of total short-chain fatty acids in feces, and they provided anti-inflammatory activity [14]. Therefore, it is desirable to develop LAB that can be used as health-promoting starters and their application to produce functional fermented foods.

As for kimchi, the development of probiotic starters has been a leading interest among microbiologists to maintain product quality and to improve the health-promoting effects of kimchi [2]. For this purpose, researchers have developed various LAB as probiotic starters, such as Bifidobacterium spp. producing conjugated linoleic acid [15] and Lactobacillus spp. producing $\gamma$-aminobutyric acid (GABA) [16]. Additionally, for the same goal, mixed starter cultures have been employed to improve the sensory quality and anticancer and antioxidant activities of kimchi [17]. However, it has been difficult for the kimchi industries to find a successful commercialization case of probiotic starter to date. After investigation of these studies as well as communication with manufacturers, we concluded that those probiotic candidates providing health-promoting effects lack suitable starter properties essential for economical production in the industry. Briefly, a candidate strain of health benefit exhibited little or no growth in kimchi, and another probiotic resulted in a quality loss after fermentation because it produced off-flavor metabolites. Based on these findings, we propose the following requirements that the probiotic candidates should meet: the probiotic must (i) grow well in a kimchi environment containing various constituents, such as garlic and ginger; (ii) grow well at low temperature; (iii) prevent over-ripening by generating optimal concentrations of organic acids; (iv) provide favorable taste and aroma of kimchi; and (v) possess health-promoting properties. To develop suitable probiotic starters for kimchi fermentation, the above hypothesis should be assessed using well-established probiotic bacteria in kimchi.

The aim of this study was to evaluate the suitability of well-known probiotics as kimchi starters to produce health-promoting products with preferred taste. To this end, 17 probiotic type strains listed in the Health Functional Food Code in Korea (Table 1) were cultivated in simulated kimchi juice (SKJ) at $37{ }^{\circ} \mathrm{C}$ or $30{ }^{\circ} \mathrm{C}$ and $15{ }^{\circ} \mathrm{C}$ for 5 days, and their growth profiles, such as optical density and $\mathrm{pH}$ changes, were analyzed. Type strains exhibiting good growth in SKJ were used as starters for kimchi fermentation, and metabolite profiles were analyzed by GC/MS and ${ }^{1} \mathrm{H}-\mathrm{NMR}$. Then, the effects of the type strains on sensory qualities were compared with kimchi fermented by a commercial starter, Leuconostoc mesenteroides DRC1506.

Table 1. List of strains used in this study.

\begin{tabular}{ccc}
\hline Species & Collections & Culture Condition ${ }^{\circ}$ C) \\
\hline Leuconostoc mesenteroides DRC1506 & KCCM11712P & 30 \\
Limosilacotobacillus fermentum & KACC11441 & 37 \\
Lactiplantibacillus plantarum & KACC11451 & 37 \\
Limosilacotobacillus reuteri & KACC11452 & 37 \\
Lacticaseibacillus rhamnosus & KACC11953 & 37 \\
Lacticaseibacillus paracasei subsp. paracasei & KACC12361 & 30 \\
Lacticaseibacillus casei & KACC12413 & 30 \\
Lactobacillus helveticus & KACC12418 & 37 \\
Lactobacillus acidophilus & KACC12419 & 37 \\
Lactobacillus gasseri & KACC12420 & 37 \\
Ligilactobacillus salivarius & KACC12424 & 37 \\
Lactococcus lactis & KACC10006 & 37 \\
KACC13877 & KACC11857 & 30 \\
Streptococcus salivarius subsp. thermophilus & KACC16638 & 37 \\
Bifidobacterium animalis subsp. lactis & KACC16639 & 37 \\
Bifidobacterium breve & KACC20601 & 37 \\
Bifidobacterium bifidum & KCTC3128 & 37 \\
Bifidobacterium longum & & 37 \\
\hline
\end{tabular}




\section{Materials and Methods}

\subsection{Microorganisms and Culture Conditions}

The bacterial strains used in this study are listed in Table 1 . The probiotic strains are known to provide health benefits when consumed, generally by improving or restoring the gut flora based on available information and scientific evidence [18-20]. They are approved as health functional food ingredients by Korean Ministry of Food and Drug Safety (MFDS). Probiotic type strains (17 species) were obtained from the Korean Agricultural Culture Collection (KACC, Wanju, Korea) or the Korean Collection for Type Cultures (KCTC, Daejeon, Korea). The commercial kimchi starter, Leuconostoc mesenteroides DRC1506, was kindly provided by Daesang FNF (Icheon, Korea). Most LAB were cultured in MRS broth (BD Difco, Detroit, MI, USA) at $37^{\circ} \mathrm{C}$ for $24 \mathrm{~h}$ under anaerobic conditions. Bifidobacterium spp. were cultured in MRS broth (BD Difco) supplemented with $0.05 \%(w / v)$ L-cysteine hydrochloride (Sigma-Aldrich, St Louis, MO, USA).

\subsection{Preparation of $S K J$}

SKJ was used as a pasteurized liquid medium simulating the kimchi environment for reproducible monitoring of microbial growth in the early stage of starter selection. SKJ was prepared according to the method described by Lee et al. [21]. Raw materials (cabbage, radish, garlic, ginger, and leek) and their contents are listed in Table 2. All materials were finely cut using a physical blender and incubated overnight after the addition of salts. Next, fish peptone (Bision, Seoul, Korea) was added instead of jeotgal (fermented fish source), and the mixture was pasteurized at $70{ }^{\circ} \mathrm{C}$ for $30 \mathrm{~min}$. After cooling down to room temperature, the mixture was centrifuged at $7000 \times g$ for $10 \mathrm{~min}$ to remove the pulp, and the supernatant was used as the SKJ in the experiments. After pasteurization of the juice, no bacterial growth was confirmed by incubating SKJ on an MRS agar plate for two days.

Table 2. Composition of simulated kimchi juice (SKJ).

\begin{tabular}{cc}
\hline Ingredients & Concentration \\
\hline Cabbage & $700 \mathrm{~g}$ \\
Radish & $200 \mathrm{~g}$ \\
Leek & $50 \mathrm{~g}$ \\
Ginger & $10 \mathrm{~g}$ \\
Garlic & $20 \mathrm{~g}$ \\
Salt & $3 \%$ \\
Fish peptone & $0.5 \%$ \\
\hline
\end{tabular}

Bacterial strains cultured in the media listed in Table 1 were washed twice with sterile phosphate-buffered saline (PBS, $\mathrm{pH}=7.2$ ), and $10^{9}$ colony forming units $(\mathrm{CFU}) / \mathrm{mL}$ were inoculated in the SKJ. After cultivating these strains at their optimal temperatures, such as 37 or $30^{\circ} \mathrm{C}$ as described in Table 1, optical density and $\mathrm{pH}$ were measured using a spectrophotometer (BioTek, Winooski, VT, USA) at $600 \mathrm{~nm}$ and a $\mathrm{pH}$ meter Orion Star A211 (Thermo Fisher Scientific Inc., MA, USA), respectively. In addition, to evaluate the adaptability of 17 probiotic $\mathrm{LAB}$ to low temperature, they were cultured at $15^{\circ} \mathrm{C}$ for 5 days under the same condition, and optical density and $\mathrm{pH}$ were monitored periodically. In industry, kimchi is often fermented and distributed at $10^{\circ} \mathrm{C}$, where the growing bacteria are greatly limited. Therefore, in this study, they were cultured at $15{ }^{\circ} \mathrm{C}$ in SKJ as a preliminary step for the broad selection of probiotic kimchi starters that grow at low temperatures.

\subsection{Preparation and Fermentation of Kimchi}

Baechu kimchi was prepared according to the commercial kimchi manufacturing method of the Daesang FNF (Icheon, Korea) as described in Korean patent No. 10-1809447 [22]. Briefly, for the desalting process, baechu cabbages were washed with tap water and soaked in $8 \%$ salt solution at room temperature for $12 \mathrm{~h}$. The salted cabbages were washed twice with tap water and then dehydrated. The salted cabbage (82.5\%) was mixed with various 
condiments, such as pepper powder $(2.5 \%)$, crushed garlic $(2 \%)$, crushed ginger $(0.5 \%)$, sliced green onion $(2 \%)$, and sliced radish $(9 \%)$. For kimchi fermentation, pre-cultured $\mathrm{LAB}$ were inoculated at a concentration of $10^{5}$ cells/g-kimchi and incubated at $10^{\circ} \mathrm{C}$. After reaching $\mathrm{pH} 4.4$, an optimum condition for the ripened state, kimchi was stored at $-0.5^{\circ} \mathrm{C}$ for sensory testing, and aliquots were frozen at $-80^{\circ} \mathrm{C}$ for metabolite analyses. For $\mathrm{pH}$ measurement, kimchi samples $(10 \mathrm{~g})$ were diluted in $90 \mathrm{~mL}$ of $0.85 \% \mathrm{NaCl}$ solution and were homogenized using the Seward Stomacher 400 Lab System (Seward, Norfolk, UK) for $3 \mathrm{~min}$. The $\mathrm{pH}$ of the kimchi samples was measured using an Orion Star A211 pH meter (Thermo Fisher Scientific Inc. Waltham, MA, USA).

\subsection{Analysis of Volatile Compounds by GC-MS}

Volatile aroma compounds were extracted using solid-phase microextraction (SPME) fibers (DVB/CAR/PDMS, 50/30 $\mu \mathrm{m}$, Supelco, 57298-U) and measured using a gas chromatography-mass spectrometer (GC/MS) (7820A/5977E MSD, Agilent Technologies, Palo Alto, CA, USA) with an Agilent GC Sampler 120 PAL autosampler. Before analysis, the injector was conditioned by exposure to $250^{\circ} \mathrm{C}$ for $60 \mathrm{~min}$. For the extraction of volatile compounds, kimchi juice $(1 \mathrm{~g})$ was placed in a headspace vial $(20 \mathrm{~mL}, 22.5 \mathrm{~mm} \times 75.5 \mathrm{~mm})$ with $1 \mathrm{~mL}$ of distilled water and stirred at $300 \times g$ at $51^{\circ} \mathrm{C}$ for $20 \mathrm{~min}$. For quantitative analysis, $10 \mu \mathrm{L}$ of $100 \mathrm{ppm}$ methyl cinnamate (Sigma-Aldrich) dissolved in ethanol were added to distilled water as an internal standard. Then, the volatile components were adsorbed onto the SPME fiber for $30 \mathrm{~min}$, and the fiber was automatically injected into the GC injector in the splitless mode for $2 \mathrm{~min}$. For the GC/MS, a DB-WAX column $(50 \mathrm{~m} \times 200 \mu \mathrm{m} \times 0.2 \mu \mathrm{m}$, Agilent Technologies) was used with helium flowing at a rate of $1.5 \mathrm{~mL} / \mathrm{min}$. The injector temperature was $250^{\circ} \mathrm{C}$, and the oven temperature was increased from $40{ }^{\circ} \mathrm{C}(5 \mathrm{~min})$ to $150{ }^{\circ} \mathrm{C}(0 \mathrm{~min})$ at a rate of $5{ }^{\circ} \mathrm{C} / \mathrm{min}$ followed by an increment to $200{ }^{\circ} \mathrm{C}(10 \mathrm{~min})$ at a rate of $7{ }^{\circ} \mathrm{C} / \mathrm{min}$. The chromatograms of volatile compounds were acquired using a scan mode of $m / z$ 33-250 at a fragment voltage of $70 \mathrm{eV}$, and peaks were identified through a library search (NIST ver. 11).

\subsection{Metabolite Analysis by ${ }^{1} H-N M R$}

When kimchi reached the optimum ripening state ( $\mathrm{pH} 4.4)$, non-volatile metabolite profiles, including organic acids, carbohydrates, and amino acids, were analyzed using ${ }^{1} \mathrm{H}-\mathrm{NMR}$ spectroscopy. Briefly, $3 \mathrm{~mL}$ of kimchi juice adjusted to $\mathrm{pH} 6.0$ were mixed with $3 \mathrm{~mL}$ of deuterium oxide solution $\left(99.9 \% \mathrm{D}_{2} \mathrm{O}\right.$; Sigma-Aldrich) containing $1 \mathrm{mM}$ sodium 2,2-dimethyl-2-silapentane-5-sulfonate (DSS; Sigma-Aldrich). The mixture was centrifuged for $5 \mathrm{~min}$ at $13,000 \times g$, and $750 \mu \mathrm{L}$ of the supernatant were transferred into a 5-mm NMR tube. Spectra were acquired using a Bruker 500-MHz NMR spectrometer (Bruker Magnetics, Faellanden, Switzerland) at $25^{\circ} \mathrm{C}$. Identification and quantification of individual metabolites from the ${ }^{1} \mathrm{H}$-NMR spectra were performed using the Profiler module of the Chenomx NMR Suite program (ver. 6.1; Chenomx, Edmonton, AB, Canada).

\subsection{Sensory Evaluation of Kimchi}

A total of 20 selected and semi-trained evaluators, the graduate students in the program of Food Sciences at Chungbuk National University, participated in the sensory evaluation of kimchi. They were trained on relevant guidelines prior to sensory evaluation. The protocol was approved by the Institutional Review Board of Chungbuk National University (IRB No. CBNU-202004-BMSB-0060-01). Optimally ripened kimchi (pH $4.4 \pm 0.1$ ) was used for testing, and the characteristics, such as sensory properties, the harmony of taste, and preferences of texture and flavor, were scored using a 9-point scale: $1=$ very bad, $5=$ moderate, and $9=$ very good .

\subsection{Statistical Analysis}

To determine significant differences, statistical analysis was performed by one-way analysis of variance (ANOVA) with Duncan's multiple range test $(p<0.05)$ using IBM SPSS 
software version 22 (SPSS Inc., Chicago, IL, USA). Principal component analysis (PCA) was performed using the prcomp command of the R statistical software (R Core Team, Vienna, Austria).

\section{Results}

\subsection{Microbial Growth Rates in Simulated Kimchi Medium}

To investigate the adaptability of 17 LAB in kimchi containing cabbage, radish, salt, and several condiments, the cell growth rates were measured in the SKJ at their optimal temperatures $\left(30\right.$ or $37^{\circ} \mathrm{C}$ ) for $24 \mathrm{~h}$ (Figure 1). The commercial starter, Le. mesenteroides DRC 1506 was cultivated simultaneously as a reference strain. Among the tested strains, six, including DRC 1506, grew $\left(\mathrm{OD}_{600}>0.4\right)$ after $24 \mathrm{~h}$ and their growth rates were in the following order: L. reuteri, L. fermentum, L. rhamnosus, Le. mesenteroides, L. salivarius, and L. paracasei. Along with their growth, $\mathrm{pH}$ values also decreased in a similar pattern. Among these strains, $L$. reuteri and L. fermentum showed superior growth rates compared with Le. mesenteroides, revealing their outstanding adaptability in nutrient environments in the SKJ. Meanwhile, the other strains, including four species of bifidobacteria, did not grow significantly in SKJ. Presumably, the medium compositions in SKJ may not have met the nutritional requirements of these strains.

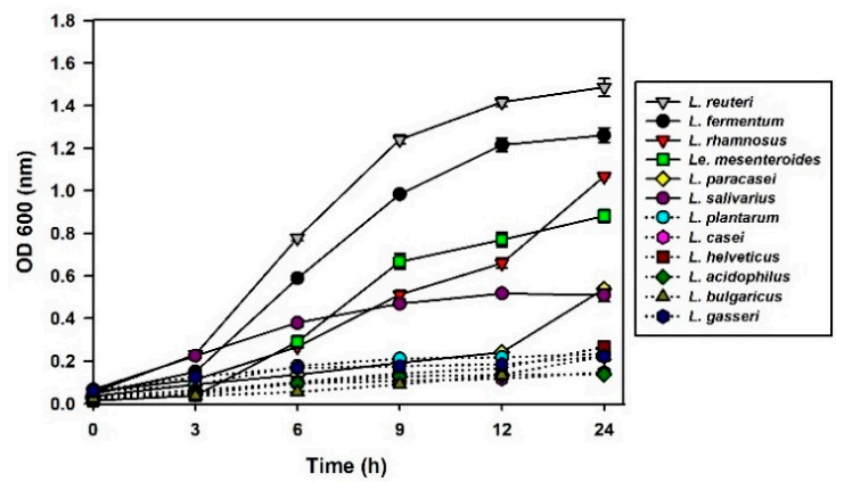

(a)

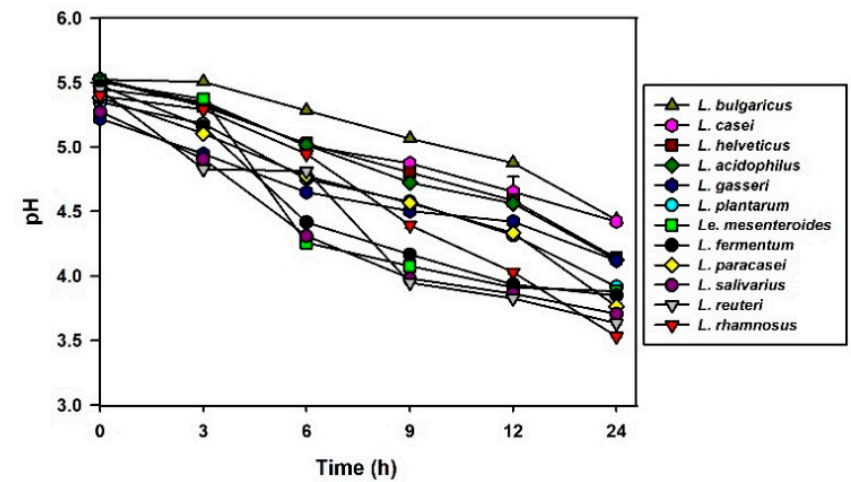

(b)

Figure 1. Cell growth $(\mathbf{a})$ and $\mathrm{pH}$ changes $(\mathbf{b})$ of the simulated kimchi juice (SKJ) after inoculation of 17 probiotic lactic acid bacteria $(\mathrm{LAB})$ at their optimal growth temperatures, 37 or $30^{\circ} \mathrm{C}$. Optical density $\left(\mathrm{OD}_{600 \mathrm{~nm}}\right)$ values and $\mathrm{pH}$ values were measured for $24 \mathrm{~h}$. The dotted lines represent little microbial growth $(<\mathrm{OD} 0.3)$ and $\mathrm{pH}$ changes $(<\mathrm{pH} 5.0)$. Results are expressed as means \pm standard deviations $(n=3)$.

Besides, the adaptability of $17 \mathrm{LAB}$ at low temperatures was tested by cultivating in SKJ at $15^{\circ} \mathrm{C}$ for 5 days (Figure 2). Among the tested strains, Le. mesenteroides showed the fastest growth rate to reach $\mathrm{OD}_{600} 0.6$ after 4 days, showing its excellent adaptability to low temperature conditions. Likewise, three strains, L. fermentum, L. rhamnosus, and L. paracasei, grew at $15{ }^{\circ} \mathrm{C}$ in the SKJ. Le. mesenteroides-inoculated SKJ reached $\mathrm{pH} 4.4$ after 1 day, which is the optimal acidity providing the preferred taste in kimchi [23]. Meanwhile, L. plantarum, L. rhamnosus, and L. paracasei took 2 days; L. casei took 4 days; and L. fermentum took 5 days (Figure 2b) to reach $\mathrm{pH}$ 4.4. Notably, L. plantarum, L. casei, L. acidophilus, and L. bulgaricus did not grow well at low temperature, but the $\mathrm{pH}$ decreased in the cultures. Compared to the other strains, Le. mesenteroides produced lactic acid more quickly. At the end of the fermentation at $15{ }^{\circ} \mathrm{C}$, the $\mathrm{pH}$ of L. rhamnosus and L. paracasei was approximately 3.7 and that of L. fermentum was about 4.2, which did not show much difference from that of Le. mesenteroides ( $\mathrm{pH}$ 3.7), indicating that an appropriate amount of acid was produced during fermentation. Therefore, L. fermentum, L. rhamnosus, and L. paracasei showed similar growth patterns to those of Le. mesenteroides. 


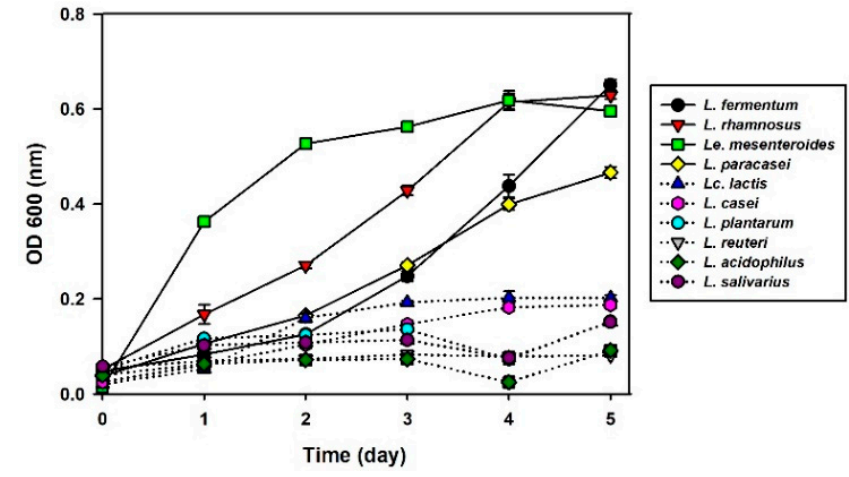

(a)

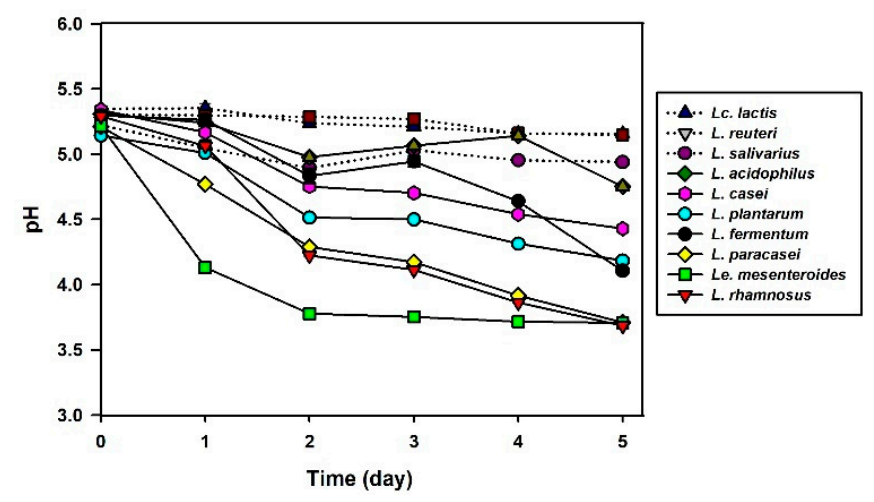

(b)

Figure 2. Cell growth (a) and $\mathrm{pH}$ changes (b) of the simulated kimchi juice (SKJ) after inoculation of 17 probiotic lactic acid bacteria $(\mathrm{LAB})$ at low temperature, $15{ }^{\circ} \mathrm{C}$. Optical density $\left(\mathrm{OD}_{600 \mathrm{~nm}}\right)$ values and $\mathrm{pH}$ values were measured for $24 \mathrm{~h}$. The dotted lines represent little microbial growth $(<\mathrm{OD} 0.3)$ and $\mathrm{pH}$ changes $(<\mathrm{pH} 5.0)$. Results are expressed as means \pm standard deviations $(n=3)$.

\subsection{Kimchi Fermentation by Inoculation of Five Strains}

Based on the results of the above experiments, five strains capable of growing in SKJ at low temperature were selected as possible candidates as kimchi probiotic starters, namely, L. fermentum, L. reuteri, L. rhamnosus, L. paracasei, and L. salivarius. To investigate their effects on the fermentation profile and sensory changes in kimchi, these five strains and the commercial starter, Le. mesenteroides, were inoculated in cabbage kimchi at a concentration of $10^{5}$ cells $/ \mathrm{g}$, and the $\mathrm{pH}$ was monitored during kimchi fermentation at $10^{\circ} \mathrm{C}$ (Figure 3). The initial $\mathrm{pH}$ of the kimchi samples was approximately 5.4 to 5.6, which did not change until the first day of fermentation, but from day 2 onwards, the $\mathrm{pH}$ of kimchi fermented with Le. mesenteroides and L. fermentum decreased rapidly and reached $\mathrm{pH} 4.4$, on day 3. Meanwhile, the $\mathrm{pH}$ of kimchi fermented with L. reuteri, L. rhamnosus, L. paracasei, and L. salivarius decreased slowly and reached the optimal $\mathrm{pH}$ range (4.2 4.5) of kimchi on day 4.

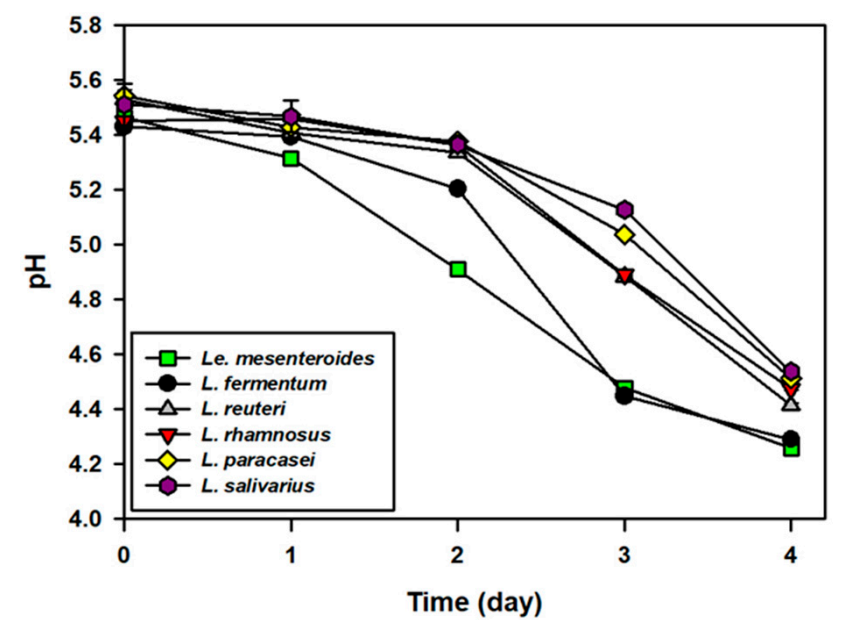

Figure 3. The $\mathrm{pH}$ changes in kimchi fermentation at $15^{\circ} \mathrm{C}$ for four days after inoculation of five probiotic lactic acid bacteria (LAB). The LAB that showed fast growth rates in simulated kimchi juice (SKJ) (Figure 1) at low temperature $\left(15^{\circ} \mathrm{C}\right)$ (Figure 2) were Limosilacotobacillus fermentum, Limosilacotobacillus reuteri, Lacticaseibacillus rhamnosus, Lacticaseibacillus paracasei subsp. paracasei, and Ligilactobacillus salivarius. Leuconostoc mesenteroides DRC 1506, a commercial kimchi starter, was used for comparison. Results are expressed as means \pm standard deviations $(n=3)$. 


\subsection{Analysis of Metabolites in Kimchi}

To evaluate the effect of starter on metabolite changes in kimchi, ${ }^{1} \mathrm{H}-\mathrm{NMR}$ analysis was conducted when they reached the optimal $\mathrm{pH}$ range (Table 3 ). The glucose content was low in both Le. mesenteroides- and L. fermentum-kimchi, revealing their rapid consumption rates for cell growth. Mannitol is a sugar alcohol produced by the reduction of fructose, which gives a fresh sweet taste in kimchi; its contents were high in Le. mesenteroides-, L. fermentum-, and $L$. reuteri-kimchi $(28.96,29.55$, and $27.79 \mathrm{mM}$, respectively) compared with other kimchi. Lactate and acetate concentrations in the Le. mesenteroides-kimchi were 24.55 and $13.92 \mathrm{mM}$, respectively, showing a typical ratio in a hetero-lactic acid fermentation. Notably, lactate concentrations were significantly low in L. rhamnosus and L. paracasei-kimchi, probably affecting the quality of sour taste. Among the 15 amino acids detected, alanine, glutamate, glutamine, glycine, and serine were the most prevalent residues $(>80 \%)$, and the glutamate content for umami taste was highest in L. reuteri-added kimchi.

A biplot of the principal component analysis (PCA) of metabolite compounds detected in kimchi is shown in Figure 4. Based on the PC1 axis, Le. mesenteroides- and L. fermentumkimchi are located on the left, while the other kimchi are located on the right. Similarly, based on the PC2 axis, Le. mesenteroides- and L. reuteri-kimchi are located at the top, while the other kimchis are located at the bottom. In detail, Le. mesenteroides and L. fermentum were highly correlated with the levels of major metabolites, such as mannitol, ethanol, lactate, and acetate, and Le. mesenteroides and L. reuteri were highly correlated with glutamate and glutamine levels. In summary, L. fermentum and L. reuteri-kimchi share a close correlation with Le. mesenteroides-kimchi in terms of metabolite composition.

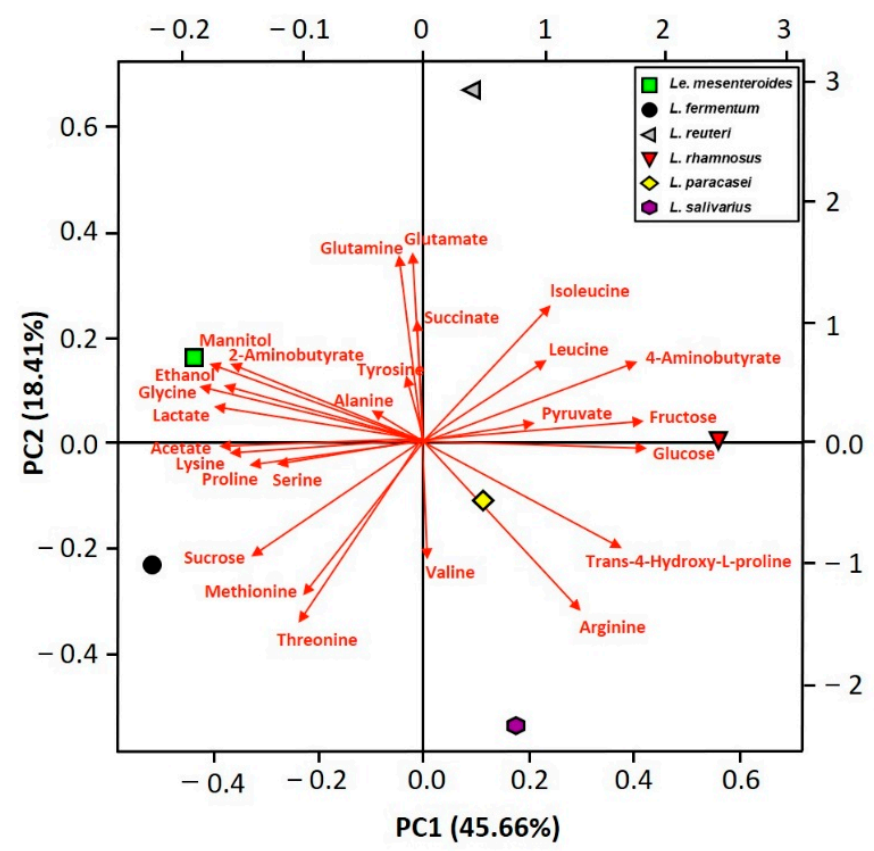

Figure 4. Biplot of the principal components analysis (PCA) of metabolite compounds detected in kimchi by ${ }^{1} \mathrm{H}$ NMR after fermentation of five lactic acid bacteria (LAB) at $15{ }^{\circ} \mathrm{C}$ for four days. Limosilacotobacillus fermentum, Limosilacotobacillus reuteri, Lacticaseibacillus rhamnosus, Lacticaseibacillus paracasei subsp. paracasei, and Ligilactobacillus salivarius were tested, and Leuconostoc mesenteroides DRC 1506, a commercial kimchi starter, was used for comparison. 
Table 3. Quantitative values (mM) of metabolites in optimal ripened kimchi samples fermented with probiotic strains.

\begin{tabular}{|c|c|c|c|c|c|c|c|}
\hline Groups & Metabolites & Le. Mesenteroides & L. Fermentum & L. Reuteri & L. Rhamnosus & L. Paracasei & L. Salivarius \\
\hline \multirow{3}{*}{ Carbohydrates } & Glucose & $27.51 \pm 1.99^{c}$ & $27.96 \pm 2.06^{c}$ & $36.62 \pm 0.39^{b}$ & $47.62 \pm 7.26^{a}$ & $32.80 \pm 1.99 \mathrm{bc}$ & $38.61 \pm 1.33^{\mathrm{ab}}$ \\
\hline & Fructose & $58.79 \pm 1.22^{b}$ & $59.21 \pm 0.40^{b}$ & $70.22 \pm 1.23^{\mathrm{a}}$ & $74.09 \pm 5.62^{\mathrm{a}}$ & $73.58 \pm 2.76^{a}$ & $67.91 \pm 0.61^{\mathrm{a}}$ \\
\hline & Sucrose & $4.28 \pm 0.86^{\mathrm{a}}$ & $4.77 \pm 0.88^{\mathrm{a}}$ & $4.14 \pm 0.78^{\mathrm{a}}$ & $4.01 \pm 0.81^{\mathrm{a}}$ & $4.45 \pm 0.07^{\mathrm{a}}$ & $4.34 \pm 0.48^{\mathrm{a}}$ \\
\hline \multirow{2}{*}{ Alcohols } & Ethanol & $16.62 \pm 1.62^{\mathrm{ab}}$ & $18.75 \pm 0.13^{\mathrm{a}}$ & $16.46 \pm 1.39 \mathrm{ab}$ & $14.17 \pm 1.44^{b}$ & $14.24 \pm 1.49^{b}$ & $14.21 \pm 0.95^{b}$ \\
\hline & Mannitol & $28.95 \pm 2.22^{\mathrm{a}}$ & $29.55 \pm 2.33^{a}$ & $27.79 \pm 1.20^{\mathrm{a}}$ & $20.10 \pm 0.83^{b}$ & $23.10 \pm 1.32^{b}$ & $23.20 \pm 0.59^{b}$ \\
\hline \multirow{5}{*}{ Organic acids } & 2-Aminobutyrate & $1.80 \pm 0.33^{\mathrm{a}}$ & $1.68 \pm 0.13^{\mathrm{a}}$ & $1.64 \pm 0.51^{\mathrm{a}}$ & $1.26 \pm 0.83^{a}$ & $1.71 \pm 0.37^{\mathrm{a}}$ & $1.38 \pm 0.50^{\mathrm{a}}$ \\
\hline & 4-Aminobutyrate & $1.93 \pm 0.02^{b}$ & $1.62 \pm 0.55^{b}$ & $4.15 \pm 0.81^{\mathrm{a}}$ & $4.15 \pm 0.48^{a}$ & $2.85 \pm 0.73^{a b}$ & $3.30 \pm 0.60^{\mathrm{a}}$ \\
\hline & Lactate & $24.55 \pm 6.72^{b}$ & $21.92 \pm 4.15^{\mathrm{ab}}$ & $19.51 \pm 1.244^{\mathrm{ab}}$ & $16.16 \pm 0.54^{\mathrm{a}}$ & $16.32 \pm 1.06^{\mathrm{a}}$ & $18.81 \pm 1.89^{a b}$ \\
\hline & Succinate & $0.81 \pm 0.24^{\mathrm{a}}$ & $1.34 \pm 0.43^{\mathrm{a}}$ & $1.70 \pm 0.10^{\mathrm{a}}$ & $0.99 \pm 0.38^{\mathrm{a}}$ & $1.01 \pm 0.51^{\mathrm{a}}$ & $1.04 \pm 0.58^{\mathrm{a}}$ \\
\hline & Pyruvate & $0.27 \pm 0.09^{a}$ & $0.20 \pm 0.08^{\mathrm{a}}$ & $0.42 \pm 0.11^{\mathrm{a}}$ & $0.29 \pm 0.14^{\mathrm{a}}$ & $0.28 \pm 0.02^{\mathrm{a}}$ & $0.45 \pm 0.25^{\mathrm{a}}$ \\
\hline \multirow{14}{*}{ Amino acids } & Alanine & $7.36 \pm 1.65^{\mathrm{a}}$ & $8.72 \pm 1.80^{\mathrm{a}}$ & $8.56 \pm 0.77^{a}$ & $7.71 \pm 0.74^{\mathrm{a}}$ & $7.89 \pm 0.22^{\mathrm{a}}$ & $7.91 \pm 1.19^{a}$ \\
\hline & Arginine & $1.86 \pm 1.42^{b}$ & $2.43 \pm 0.27^{b}$ & $1.88 \pm 0.20^{\mathrm{ab}}$ & $3.85 \pm 0.29^{a}$ & $2.60 \pm 0.51^{\mathrm{ab}}$ & $3.90 \pm 0.50^{\mathrm{a}}$ \\
\hline & Glutamate & $9.95 \pm 3.12^{a b}$ & $11.49 \pm 0.28^{a b}$ & $13.49 \pm 0.81^{\mathrm{a}}$ & $10.59 \pm 0.73^{\mathrm{ab}}$ & $10.04 \pm 0.18^{\mathrm{ab}}$ & $8.93 \pm 1.91^{b}$ \\
\hline & Glutamine & $13.69 \pm 3.68^{a}$ & $9.42 \pm 3.22^{\mathrm{a}}$ & $12.85 \pm 1.22^{\mathrm{a}}$ & $11.60 \pm 0.44^{\mathrm{a}}$ & $10.04 \pm 0.58^{a}$ & $9.50 \pm 0.87^{\mathrm{a}}$ \\
\hline & Glycine & $5.74 \pm 4.35^{\mathrm{a}}$ & $5.37 \pm 1.17^{\mathrm{a}}$ & $4.34 \pm 0.70^{\mathrm{a}}$ & $1.70 \pm 1.34^{\mathrm{a}}$ & $4.03 \pm 0.95^{\mathrm{a}}$ & $3.01 \pm 0.41^{\mathrm{a}}$ \\
\hline & Leucine & $0.83 \pm 0.22^{\mathrm{a}}$ & $0.80 \pm 0.36^{\mathrm{a}}$ & $1.70 \pm 0.86^{\mathrm{a}}$ & $1.06 \pm 0.64^{\mathrm{a}}$ & $1.20 \pm 0.40^{\mathrm{a}}$ & $1.40 \pm 0.70^{\mathrm{a}}$ \\
\hline & Lysine & $1.70 \pm 1.02^{\mathrm{a}}$ & $1.16 \pm 0.27^{\mathrm{a}}$ & $0.75 \pm 0.44^{\mathrm{a}}$ & $0.64 \pm 0.50^{\mathrm{a}}$ & $0.92 \pm 0.23^{a}$ & $0.92 \pm 0.08^{\mathrm{a}}$ \\
\hline & Methionine & $0.62 \pm 0.06^{\mathrm{a}}$ & $1.20 \pm 0.08^{\mathrm{a}}$ & $0.56 \pm 0.24^{\mathrm{a}}$ & $0.31 \pm 0.08^{\mathrm{a}}$ & $0.99 \pm 0.16^{\mathrm{a}}$ & $1.09 \pm 0.12^{\mathrm{a}}$ \\
\hline & Proline & $2.67 \pm 1.08^{\mathrm{a}}$ & $2.62 \pm 0.75^{\mathrm{a}}$ & $2.24 \pm 0.33^{\mathrm{a}}$ & $1.76 \pm 1.07^{\mathrm{a}}$ & $1.62 \pm 0.68^{a}$ & $2.50 \pm 0.76^{\mathrm{a}}$ \\
\hline & Serine & $15.70 \pm 0.99 \mathrm{ab}$ & $15.77 \pm 0.79 \mathrm{ab}$ & $15.82 \pm 1.78^{a b}$ & $11.66 \pm 0.95^{b}$ & $14.95 \pm 2.03^{\mathrm{ab}}$ & $16.50 \pm 3.55^{\mathrm{a}}$ \\
\hline & trans-4-Hydroxy-L-proline & $0.31 \pm 0.10^{c}$ & $1.08 \pm 0.20^{\mathrm{bc}}$ & $1.80 \pm 1.18^{\mathrm{abc}}$ & $2.94 \pm 1.74^{\mathrm{ab}}$ & $2.34 \pm 0.59^{\mathrm{ab}}$ & $3.61 \pm 1.39^{\mathrm{a}}$ \\
\hline & Threonine & $2.74 \pm 0.99^{\mathrm{a}}$ & $3.94 \pm 0.84^{\mathrm{a}}$ & $1.46 \pm 1.13^{\mathrm{a}}$ & $1.72 \pm 1.53^{\mathrm{a}}$ & $2.05 \pm 1.73^{\mathrm{a}}$ & $3.89 \pm 1.11^{\mathrm{a}}$ \\
\hline & Tyrosine & $0.45 \pm 0.06^{\mathrm{a}}$ & $0.46 \pm 0.07^{\mathrm{a}}$ & $0.42 \pm 0.11^{\mathrm{a}}$ & $0.47 \pm 0.04^{\mathrm{a}}$ & $0.55 \pm 0.16^{\mathrm{a}}$ & $0.29 \pm 0.13^{a}$ \\
\hline & Valine & $0.64 \pm 0.43^{\mathrm{a}}$ & $1.27 \pm 0.30^{\mathrm{a}}$ & $0.91 \pm 0.47^{\mathrm{a}}$ & $1.00 \pm 0.63^{\mathrm{a}}$ & $0.75 \pm 0.44^{\mathrm{a}}$ & $1.14 \pm 0.53^{\mathrm{a}}$ \\
\hline
\end{tabular}

The different superscript letters indicate significant difference $(p<0.05)$ in the concentration of each metabolite. 


\subsection{Analysis of Volatile Aroma Compounds}

To examine the effect of starters on the aroma profiles of kimchi, the volatile compounds in the kimchi were analyzed by GC/MS when their pH reached the optimally ripened condition (Table 4). Seventeen compounds were detected, which were mostly sulfur compounds, such as dimethyl disulfide, diallyl sulfide, methyl 1-propenyl disulfide, methyl 2-propenyl disulfide, dimethyl trisulfide, diallyl disulfide, methyl 2-propenyl trisulfide, and methyl methylthiomethyl disulfide. The total amount of volatile compounds was lowest in Le. mesenteroides-kimchi $(556.25 \pm 14.68 \mathrm{ppm})$ and the levels were in the order of $<$ L. reuteri $(584.60 \pm 32.49 \mathrm{ppm})<$ L. rhamnosus $(657.38 \pm 25.61 \mathrm{ppm})$ $<$ L. fermentum $(673.70 \pm 36.52 \mathrm{ppm})<$ L. paracasei $(875.84 \pm 27.07 \mathrm{ppm})<$ L. salivarius $(972.43 \pm 18.71 \mathrm{ppm})$. In detail, the amounts of methyl 2-propenyl disulfide and diallyl disulfide were significantly lower in kimchi fermented with Le. mesenteroides and L. reuteri, and higher in kimchi fermented with L. salivarius. Notably, cyclopentyl isothiocyanate, which has a pungent odor, was low in kimchi fermented with Le. mesenteroides, L. fermentum, and $L$. reuteri, and high in kimchi fermented with $L$. paracasei and L. salivarius.

The profiles of all volatile compounds in the ripened kimchi samples were compared using PCA analysis. As shown in Figure 5, the kimchi fermented with Le. mesenteroides, L. fermentum, and L. reuteri were located on the top-left section of the biplot, while others were located on the right side where large amounts of sulfur compounds existed. The PCA biplot showed that Le. mesenteroides, L. fermentum, and L. reuteri had a high correlation with their volatile compound compositions, and relatively low amounts of sulfur compounds in the kimchi resulted in differences between kimchi samples.

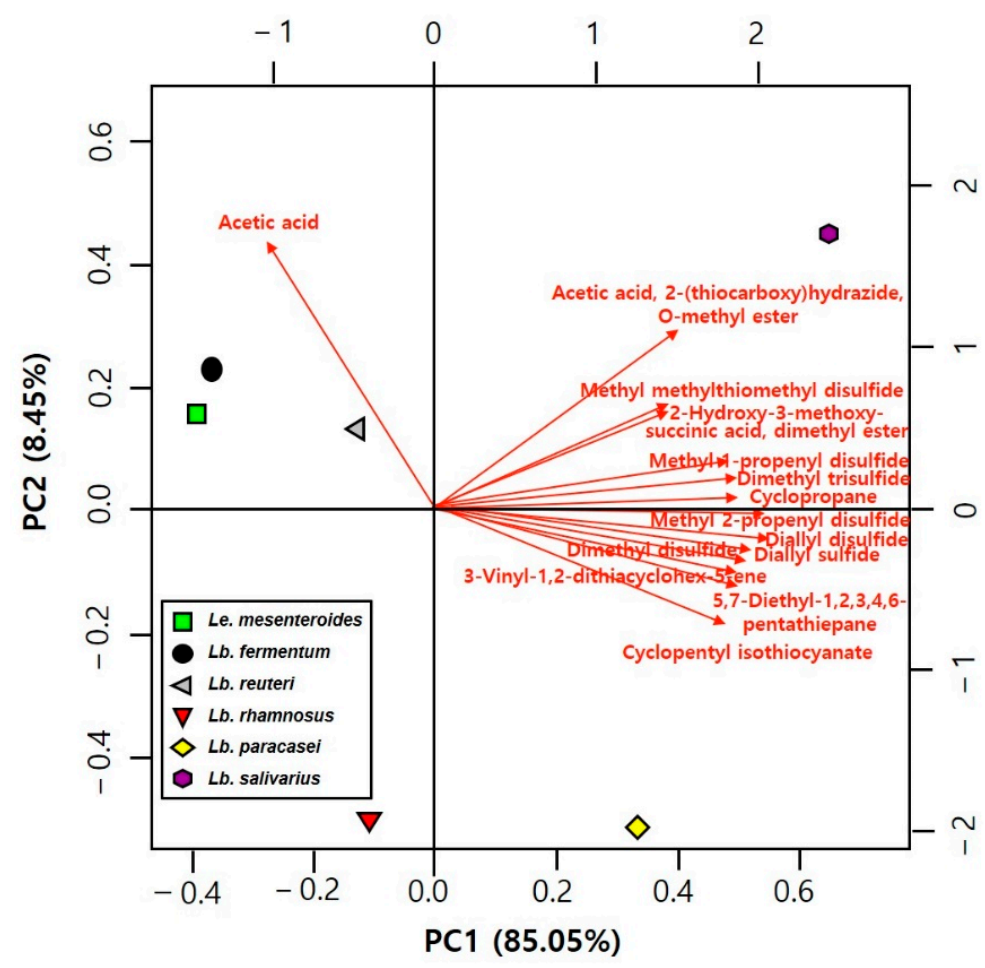

Figure 5. Biplot of the principal components analysis (PCA) on the volatile aroma compounds detected in baechu kimchi by GC/MS after fermentation of five lactic acid bacteria (LAB) at $15^{\circ} \mathrm{C}$ for four days. Limosilacotobacillus fermentum, Limosilacotobacillus reuteri, Lacticaseibacillus rhamnosus, Lacticaseibacillus paracasei subsp. paracasei, and Ligilactobacillus salivarius were tested, and Leuconostoc mesenteroides DRC 1506, a commercial kimchi starter, was used for comparison. 
Table 4. Quantitative values (ppm) of volatile aroma compounds in optimally ripened kimchi samples fermented with probiotic strains.

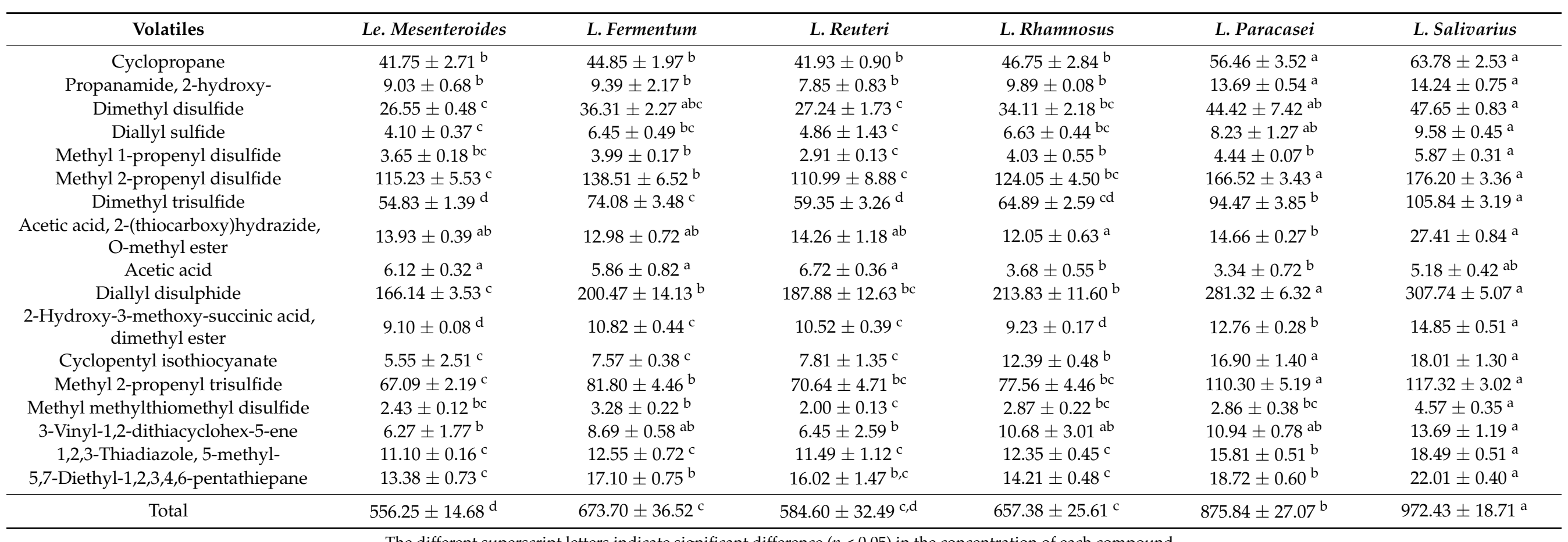

The different superscript letters indicate significant difference $(p<0.05)$ in the concentration of each compound. 


\subsection{Sensory Evaluation}

A sensory test was conducted to evaluate the effect of different starters on kimchi taste (Figure 6). No differences were observed in the textural properties of cabbages between kimchi samples at optimal acidity, and the results indicated that the addition of starter did not significantly affect the physical properties of the kimchi $(p<0.05)$. However, as the result of the harmony of taste, Le. mesenteroides, L. fermentum, and L. reuteri were evaluated at 7.35, 6, and 5.45, respectively, and L. rhamnosus, L. paracasei, and L. salivarius were evaluated relatively low at $4.55,4.25$, and 4.2 , respectively. Moreover, as a result of the overall preference evaluation, Le. mesenteroides, L. fermentum, and L. reuteri were evaluated at 7.6, 6.55, and 5.65, respectively, whereas L. rhamnosus, L. paracasei, and L. salivarius were scored relatively low at 4.5,4.4, and 4.25, respectively. Overall, Le. mesenteroides was the most preferred kimchi starter, and L. fermentum and L. reuteri showed relatively high sensory properties. In particular, L. fermentum was not significantly different from that of Le. mesenteroides.

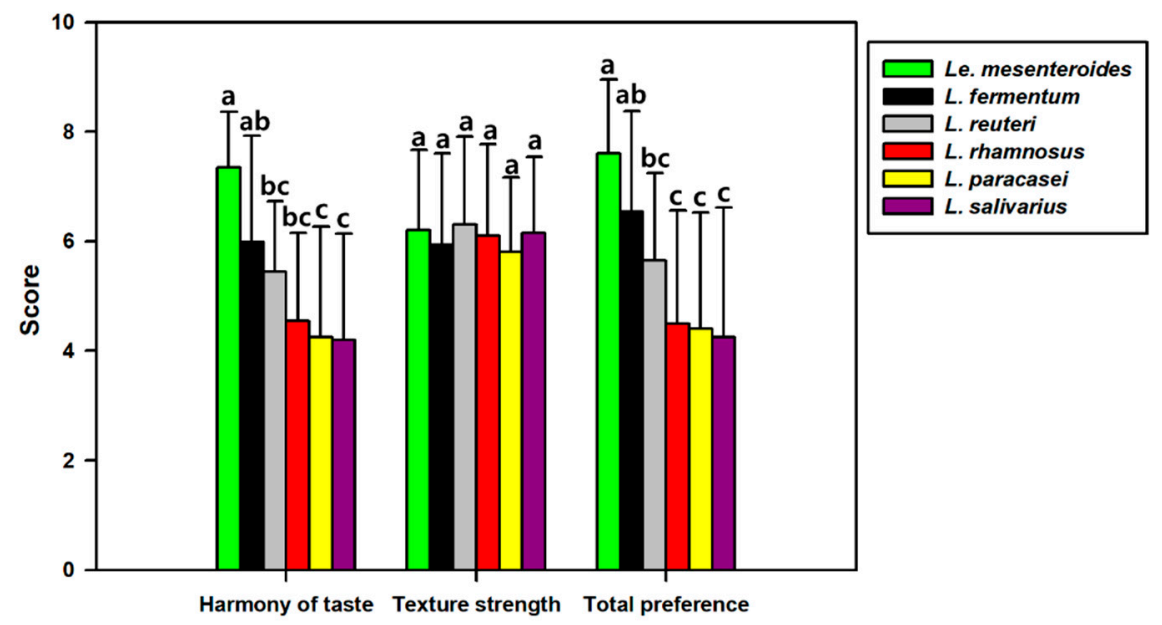

Figure 6. Sensory evaluation results of optimally ripened kimchi fermented by five lactic acid bacteria (LAB) at $15{ }^{\circ} \mathrm{C}$ for four days. Limosilacotobacillus fermentum, Limosilacotobacillus reuteri, Lacticaseibacillus rhamnosus, Lacticaseibacillus paracasei subsp. paracasei, and Ligilactobacillus salivarius were tested, and Leuconostoc mesenteroides DRC 1506, a commercial kimchi starter, was used for comparison. Results are expressed as means \pm standard error of the mean $(n=20)$. Different letters indicate a significant difference at $p<0.05$ according to Duncan's multiple range test.

\section{Discussions}

Dairy products are usually fermented by primary starter LAB species, such as Streptococcus thermophilus, Lactococcus lactis, and Lactobacillus delbrueckii spp. bulgaricus [24,25]. These starter cultures are primarily used to produce lactic acid from lactose and may not necessarily possess probiotic properties [25]. In addition to the starter culture microorganisms, various probiotics, such as Lacticaseibacillus casei-group, can be added as adjunctive and/or secondary starters to improve the health functionality of fermented products $[25,26]$. Mixed culture fermentations provide complex growth patterns, which can also positively affect the organoleptic properties of the products [27]. Similarly, the application of carefully selected strains as functional starter cultures or co-cultures in kimchi fermentation processes will help to achieve the desired properties in situ, preserving a perfectly natural and healthy product. However, little research has been done on the effect of applying a mixed culture of commercial kimchi starter and probiotic strains on kimchi.

In this study, we evaluated the suitability of 17 probiotic type strains of LAB listed in the Health Functional Food Code in Korea as kimchi starters. Among the tested strains, L. fermentum KACC 11441 and L. reuteri KACC 11452 satisfied the four conditions that are necessary as a kimchi starter showing similar fermentation properties as those of Le. mesenteroides DRC 1506. In detail, the two species grew well in kimchi at low temperature, 
generated optimal concentrations of organic acids (lactate and acetate) by hetero-lactate fermentation, and provided the preferred taste and aroma of kimchi. Starter cultures used in kimchi need to adapt well to the unique environment of kimchi fermentation, which includes low temperature, low $\mathrm{pH}$, and the presence of $\mathrm{NaCl}$. Commercial kimchi products are typically distributed at low temperatures, and the organoleptic quality of kimchi fermented at low temperatures is superior to that of kimchi fermented at room temperature [2]. In addition, the taste of kimchi is mainly attributed to its metabolites, including sugars (glucose, fructose, and mannitol), organic acids (lactate and acetate), amino acids (glutamate), and $\mathrm{CO}_{2}$ (carbonate taste), and their contents are affected by the kimchi starter or microbial community during fermentation $[3,6,28]$. The main free sugars detected are glucose and fructose, which are important carbon sources metabolized by LAB during kimchi fermentation [3]. Notably, the high glucose content in L. rhamnosus-kimchi resulted in poor microbial growth during fermentation. Mannitol improves the taste of kimchi with a soft sweet taste that gives kimchi a refreshing sensation and suppresses the excessive sourness of kimchi [6,29]. This study demonstrates that L. fermentum- and L. reuteri-kimchi contained similar concentrations of glucose, mannitol, ethanol, lactate, acetate, and glutamate as those of the commercial kimchi fermented using Le. mesenteroides DRC 1506 starter. Moreover, sulfur compounds are the main volatile components of kimchi that are mainly derived from secondary ingredients, such as cabbage, garlic, and green onions. They play an important role in determining the quality of kimchi products because of their low threshold values and characteristic strong aroma [30]. Excessive amounts of sulfur compounds lower the sensory properties of kimchi, and some of the volatile compounds are regarded as off-flavors [31]. For instance, isothiocyanates are the major sulfur compounds responsible for the pungent flavor of cabbage, cauliflower, and collard greens, and they are produced by enzymatic hydrolysis of glucosinolates in these vegetables [32] The optimal concentration of sulfur compounds with low levels of off-flavor chemicals is recommended for the preferred flavor of kimchi. Taken together, our results reveal that kimchi samples fermented by L. fermentum and L. reuteri have aroma compounds similar to those of commercial kimchi fermented by Le. mesenteroides. When the two species werecompared, $L$ fermentum KACC 11441 showed the highest suitability as a kimchi starter because it grew faster at low temperature and showed similar total preferences with L. mesenteroides in sensory evaluation. Regarding the health-promoting effects of these species, additional analyses should be conducted, even though the Health Functional Food Code in Korea generally recognizes the health effects of strains belonging to the species of L. fermentum and L. reuteri.

L. fermentum and L. reuteri are Gram-positive, facultative anaerobic, and heterofermentative LAB. They are found in fermented vegetables, milk products, and human feces $[33,34]$. Recently, several studies have reported that $L$. fermentum is a good starter culture for traditional fermented vegetables in Vietnam and Africa $[35,36]$. L. reuteri has been used for the fermentation of pineapple, pumpkin, and oat-based juices, with no negative effects on the flavor [37-39]. Additionally, L. fermentum and L. reuteri strains have been proved to possess several health functionalities: they can tolerate acid and bile, adhere to the intestinal mucosa [40,41], lower cholesterol levels [42,43], ameliorate colonic inflammation [44,45], and prevent respiratory tract infections [46,47].

The limitation of this study is that type strains were used to test the suitability of LAB as kimchi starters. Type strains are descendants of the original isolates, which exhibit all the relevant phenotypic and genotypic properties listed in the original taxonomic circumscriptions published [48]. Recent studies have shown that the microbiological and biochemical characteristics differ strain specifically according to subspecies. For example, two L. plantarum subspecies isolated from kimchi had different characteristics [49], two Lactococcus lactis subspecies differed in response to stress [50], and two B. longum subspecies exhibited different inhibitory effects in a DSS-induced colitis mouse model [51]. Therefore, the results of this study only provide the general phenotypic and genotypic characteristics of the species tested, and for the development of superior starters for kimchi fermentation, 
further screening studies should be conducted against isolates belonging to L. fermentum and L. reuteri.

\section{Conclusions}

In this study, we evaluated the suitability of 17 probiotic type strains listed in the Health Functional Food Code in Korea for use as starters in kimchi. After five strains exhibiting good growth in SKJ were inoculated in kimchi, metabolite profiles and sensory qualities were compared to those of Le. mesenteroides DRC1506-kimchi. Our results show that $L$. fermentum and L. reuteri could be considered as possible candidates as kimchi starters. The two strains grew well in SKJ at low temperature and generated optimal concentrations of organic acids (lactate and acetate) providing the preferred taste and aroma of kimchi. L. fermentum and L. reuteri strains are known to have several health-related properties, such as acid-bile tolerance, intestinal adhesion, cholesterol-lowering ability, anti-inflammatory activity, and antimicrobial activity. To develop superior starters for kimchi fermentation to provide both good flavor and probiotic effects, further studies should be performed against isolates belonging to L. fermentum and L. reuteri.

Author Contributions: Data curation, H.S., G.K., S.-A.K. and B.H.R.; Methodology, S.-A.K. and B.H.R.; Supervision, N.S.H.; Writing—original draft, H.S. and G.K.; Writing—review and editing, J.-H.B. and N.S.H. All authors contributed to data interpretation. All authors have read and agreed to the published version of the manuscript.

Funding: This research was supported by Korea Institute of Planning and Evaluation for Technology in Food, Agriculture, Forestry, and Fisheries (IPET) through Agricultural Microbiome R\&D Program, funded by Ministry of Agriculture, Food and Rural Affairs (MAFRA) (918006-04-3-SB010).

Institutional Review Board Statement: The protocol for the sensory evaluation was approved by the Institutional Review Board of Chungbuk National University (IRB No. CBNU-202004-BMSB-0060-01).

Informed Consent Statement: Informed consent was obtained from all subjects involved in the study.

Data Availability Statement: The data in this study will be available upon request from the corresponding author.

Conflicts of Interest: Byung Hee Ryu is employed at the Daesang Corporation Research Institute. The authors declare no other conflict of interest.

\section{References}

1. Jang, D.J.; Chung, K.R.; Yang, H.J.; Kim, K.S.; Kwon, D.Y. Discussion on the origin of kimchi, representative of Korean unique fermented vegetables. J. Ethn. Foods 2015, 2, 126-136. [CrossRef]

2. Lee, M.E.; Jang, J.Y.; Lee, J.H.; Park, H.W.; Choi, H.J.; Kim, T.W. Starter cultures for kimchi fermentation. J. Microbiol. Biotechnol. 2015, 25, 559-568. [CrossRef] [PubMed]

3. Jeong, S.H.; Lee, H.J.; Jung, J.Y.; Lee, S.H.; Seo, H.Y.; Park, W.S.; Jeon, C.O. Effects of red pepper powder on microbial communities and metabolites during kimchi fermentation. Int. J. Food Microbiol. 2013, 160, 252-259. [CrossRef]

4. Chang, J.Y.; Chang, H.C. Improvements in the quality and shelf life of kimchi by fermentation with the induced bacteriocinproducing strains, Leuconostoc citreum GJ7 as a starter. J. Food Sci. 2010, 75, M103-M110. [CrossRef] [PubMed]

5. Jo, S.Y.; Choi, E.A.; Lee, J.J.; Chang, H.C. Characterization of starter kimchi fermented with Leuconostoc kimchii GJ2 and its cholesterol-lowering effects in rats fed a high-fat and high-cholesterol diet. J. Sci. Food Agric. 2015, 95, 2750-2756. [CrossRef] [PubMed]

6. Jung, J.Y.; Lee, S.H.; Lee, H.J.; Seo, H.Y.; Park, W.S.; Jeon, C.O. Effects of Leuconostoc mesenteroides starter cultures on microbial communities and metabolites during kimchi fermentation. Int. J. Food Microbiol. 2012, 153, 378-387. [CrossRef] [PubMed]

7. Jeong, E.J.; Moon, D.W.; Oh, J.S.; Moon, J.S.; Seong, H.; Kim, K.Y.; Han, N.S. Development of cabbage juice medium for industrial production of Leuconostoc mesenteroides starter. J. Microbiol. Biotechnol. 2017, 27, 2112-2118. [CrossRef]

8. Lee, M.; Song, J.H.; Shim, W.B.; Chang, J.Y. DNAzyme-based quantitative loop-mediated isothermal amplification for strainspecific detection of starter kimchi fermented with Leuconostoc mesenteroides WiKim32. Food Chem. 2020, 333, 127343. [CrossRef]

9. Cho, S.K.; Lee, S.J.; Shin, S.Y.; Moon, J.S.; Li, L.; Joo, W.; Kang, D.K.; Han, N.S. Development of bil salt-resistant Leuconostoc citreum by expression of bile salt hydrolase gene. J. Microbiol. Biotechnol. 2015, 25, 2100-2105. [CrossRef]

10. Guidelines for the Evaluation of Probiotics in Food. Available online: http://www.who.int/foodsafety/fs_management/en/ probiotic_guidelines.pdf (accessed on 5 May 2021). 
11. Hill, C.; Guarner, F.; Reid, G.; Gibson, G.R.; Merenstein, D.J.; Pot, B.; Morelli, L.; Canani, R.B.; Flint, H.J.; Salminen, S.; et al. The International Scientific Association for Probiotics and Prebiotics consensus statement on the scope and appropriate use of the term probiotic. Nat. Rev. Gastroenterol. Hepatol. 2014, 11, 506-514. [CrossRef]

12. Tamang, J.P.; Cotter, P.D.; Endo, A.; Han, N.S.; Kort, R.; Liu, S.Q.; Mayo, B.; Westerick, N.; Hutkins, R. Fermented foods in a global age: East meets West. Compr. Rev. Food Sci. Food Saf. 2020, 19, 184-217. [CrossRef]

13. Sauer, M.; Han, N.S. Lactic acid bacteria: Little helpers for many human tasks. Essays Biochem. 2021, EBC20200133. [CrossRef]

14. Rabah, H.; Ferret-Bernard, S.; Huang, S.; Normand, L.L.; Cousin, F.J.; Gaucher, F.; Jeantet, R.; Boudry, G.; Jan, G. The cheese matrix modulates the immunomodulatory properties of Propionibacterium freudenreichii CIRM-BIA 129 in healthy piglets. Front. Microbiol. 2018, 9, 2584. [CrossRef]

15. Min, S.G.; Kim, J.H.; Kim, S.M.; Shin, H.S.; Hong, G.H.; Oh, D.G.; Kim, K. Manufactures of functional kimchi using Bifidobacterium strain producing conjugated linoleic acid (CLA) as starter. Korean J. Food Sci. Technol. 2003, 35, 111-114.

16. Seok, J.H.; Park, K.B.; Kim, Y.H.; Bae, M.O.; Lee, M.K.; Oh, S.H. Production and characterization of kimchi with enhanced levels of $\gamma$-aminobutyric acid. Food Sci. Biotechnol. 2008, 17, 940-946.

17. Bong, Y.J.; Jeong, J.K.; Park, K.Y. Fermentation properties and increased health functionality of kimchi by kimchi lactic acid bacteria starters. J. Korean Soc. Food Sci. 2013, 42, 1717-1726. [CrossRef]

18. Standards and Specifications of Health Functional Foods. Available online: https://www.mfds.go.kr/files/upload/eng/7_ Health\%20Functioanl\%20Food\%20Code.pdf (accessed on 5 May 2021).

19. de Melo Pereira, G.V.; de Oliveira Coelho, B.; Magalhães Júnior, A.I.; Thomaz-Soccol, V.; Soccol, C.R. How to select a probiotic? A review and update of methods and criteria. Biotechno. Adv. 2018, 36, 2060-2076. [CrossRef] [PubMed]

20. Kerry, R.G.; Patra, J.K.; Gouda, S.; Park, Y.; Shin, H.S.; Das, G. Benefaction of probiotics for human health: A review. J. Food Drug Anal. 2018, 26, 927-939. [CrossRef] [PubMed]

21. Lee, M.; Song, J.H.; Jung, M.Y.; Lee, S.H.; Chang, J.Y. Large-scale targeted metagenomics analysis of bacterial ecological changes in 88 kimchi samples during fermentation. Food Microbiol. 2017, 66, 173-183. [CrossRef] [PubMed]

22. Choi, H.Y.; Ryu, B.H.; Kim, D.H. Leuconostoc mesenteroides DRC1506 and Use Thereof. Korean Patent 101,809,447, 11 December 2017.

23. Jang, J.Y.; Lee, M.E.; Lee, H.W.; Lee, J.H.; Park, H.W.; Choi, H.J.; Pyun, Y.R.; Kim, T.W. Extending the shelf life of kimchi with Lactococcus lactis strain as a starter culture. Food Sci. Biotechnol. 2015, 24, 1049-1053. [CrossRef]

24. Harris, L.J.; Fleming, H.P.; Klaenhammer, T.R. Novel paired starter culture system for sauerkraut, consisting of a nisin-resistant Leuconostoc mesenteroides strain and a nisin-producing Lactococcus lactis strain. Appl. Environ. Microbiol. 1992, 58, 1484-1489. [CrossRef]

25. Ranadheera, C.S.; Vidanarachchi, J.K.; Rocha, R.S.; Cruz, A.G.; Ajlouni, S. Probiotic delivery through fermentation: Dairy vs. non-dairy beverages. Fermentation 2017, 3, 67. [CrossRef]

26. Bancalari, E.; Castellone, V.; Bottari, B.; Gatti, M. Wild Lactobacillus casei group strains: Potentiality to ferment plant derived juices Foods 2020, 9, 314. [CrossRef]

27. Souza, C.H.B.; Saad, S.M.I. Viability of Lactobacillus acidophilus La-5 added solely or in co-culture with a yoghurt starter culture and implications on physico-chemical and related properties of Minas fresh cheese during storage. LWT 2009, 42, 633-640. [CrossRef]

28. Jung, M.Y.; Kim, T.W.; Lee, C.; Kim, J.Y.; Song, H.S.; Kim, Y.B. Role of jeotgal, a Korean traditional fermented fish sauce, in microbial dynamics and metabolite profiles during kimchi fermentation. Food Chem. 2018, 265, 135-143. [CrossRef]

29. Kim, M.J.; Lee, H.W.; Lee, M.E.; Roh, S.W.; Kim, T.W. Mixed starter of Lactococcus lactis and Leuconostoc citreum for extending kimchi shelf-life. J. Microbiol. 2019, 57, 479-484. [CrossRef] [PubMed]

30. Hawer, W.S.; Ha, J.; Hwang, J.; Nam, Y. Effective separation and quantitative analysis of major heat principles in red pepper by capillary gas chromatography. Food Chem. 1994, 49, 99-103. [CrossRef]

31. Hong, E.J.; Kim, Y.J.; Noh, B.S. The Reduction of "off-flavor" in cheonggukjang and kimchi. J. Korean Soc. Food Cult. 2010, 25, 324-333.

32. Wieczorek, M.N.; Jeleń, H.H. Volatile compounds of selected raw and cooked Brassica vegetables. Molecules 2019, $24,391$. [CrossRef] [PubMed]

33. $\mathrm{Mu}$, Q.; Tavella, V.J.; Luo, X.M. Role of Lactobacillus reuteri in human health and diseases. Front. Immunol. 2018, 9, 757. [CrossRef] [PubMed]

34. Zhao, Y.; Hong, K.; Zhao, J.; Zhang, H.; Zhai, Q.; Chen, W. Lactobacillus fermentum and its potential immunomodulatory properties. J. Funct. Foods 2019, 56, 21-32. [CrossRef]

35. Nguyen, D.T.L.; Hoorde, K.V.; Cnockaert, M.; Brandt, E.D.; Aerts, M.; Thanh, L.B.; Vandamme, P. A description of the lactic acid bacteria microbiota associated with the production of traditional fermented vegetables in Vietnam. Int. J. Food Microbiol. 2013, 163, 19-27. [CrossRef]

36. Wafula, E.N.; Brinks, E.; Becker, B.; Huch, M.; Trierweiler, B.; Mathara, J.M.; Oguntoyinbo, F.A.; Cho, G.S.; Franz, C.M.A.P. Draft Genome Sequence of Lactobacillus fermentum BFE 6620, a potential starter culture for African vegetable doods, isolated from fermented Cassava. Genome Announc. 2017, 5, e00801-17. [CrossRef]

37. Donkor, O.N.; Henriksson, A.; Vasiljevic, T.; Shah, N.P. $\alpha$-Galactosidase and proteolytic activities of selected probiotic and dairy cultures in fermented soymilk. Food Chem. 2007, 104, 10-20. [CrossRef] 
38. Semjonovs, P.; Denina, I.; Fomina, A.; Sakirova, L.; Auzina, L.; Patetko, A. Evaluation of Lactobacillus reuteri strains for Pumpkin (Cucurbita pepo L.) juice fermentation. Biotechnology 2013, 12, 202-208. [CrossRef]

39. Perricone, M.; Bevilacqua, A.; Altieri, C.; Sinigaglia, M.; Corbo, M.R. Challenges for the production of probiotic fruit juices. Beverages 2015, 1, 95-103. [CrossRef]

40. Varma, P.; Dinesh, K.R.; Menon, K.K.; Biswas, R. Lactobacillus fermentum isolated from human colonic mucosal biopsy inhibits the growth and adhesion of enteric and foodborne pathogens. J. Food Sci. 2010, 75, M546-M551. [CrossRef] [PubMed]

41. Walsham, A.D.S.; MacKenzie, D.A.; Cook, V.; Wemyss-Holden, S.; Hews, C.L.; Juge, N.; Schüller, S. Lactobacillus reuteri inhibition of enteropathogenic Escherichia coli adherence to human intestinal epithelium. Front. Microbiol. 2016, 7, 244. [CrossRef]

42. Jones, M.L.; Martoni, C.J.; Prakash, S. Cholesterol lowering and inhibition of sterol absorption by Lactobacillus reuteri NCIMB 30242: A randomized controlled trial. Eur. J. Clin. Nutr. 2012, 66, 1234-1241. [CrossRef]

43. Pan, D.D.; Zeng, X.Q.; Yan, Y.T. Characterisation of Lactobacillus fermentum SM-7 isolated from koumiss, a potential probiotic bacterium with cholesterol-lowering effects. J. Sci. Food Agric. 2011, 91, 512-518. [CrossRef]

44. Gao, C.; Major, A.; Rendon, D.; Lugo, M.; Jackson, V.; Shi, Z.; Mori-Akiyama, Y.; Versalovic, J. Histamine H2 receptor-mediated suppression of intestinal inflammation by probiotic Lactobacillus reuteri. mBio 2015, 6, e01358-15. [CrossRef] [PubMed]

45. Jang, Y.J.; Kim, W.K.; Han, D.H.; Lee, K.; Ko, G. Lactobacillus fermentum species ameliorate dextran sulfate sodium-induced colitis by regulating the immune response and altering gut microbiota. Gut Microbes 2019, 10, 696-711. [CrossRef]

46. García, A.; Navarro, K.; Sanhueza, E.; Pineda, S.; Pastene, E.; Quezada, M.; Henríquez, K.; Karlyshev, A.; Villena, J.; González, C. Characterization of Lactobacillus fermentum UCO-979C, a probiotic strain with a potent anti-Helicobacter pylori activity. Electron. J. Biotechnol. 2017, 25, 75-83. [CrossRef]

47. Gutierrez-Castrellon, P.; Lopez-Velazquez, G.; Diaz-Garcia, L.; Jimenez-Gutierrez, C.; Mancilla-Ramirez, J.; Estevez-Jimenez, J.; Parra, M. Diarrhea in preschool children and Lactobacillus reuteri: A randomized controlled trial. Pediatrics 2014, 133, e904-e909. [CrossRef] [PubMed]

48. Kyrpides, N.C.; Hugenholtz, P.; Eisen, J.A.; Woyke, T.; Göker, M.; Parker, C.T.; Amann, R.; Beck, B.J.; Chain, P.S.G.; Chun, J.; et al. Genomic encyclopedia of bacteria and archaea: Sequencing a myriad of type strains. PLoS Biol. 2014, 12, e1001920. [CrossRef]

49. Jin, Y.J.; Park, Y.K.; Cho, M.S.; Lee, E.S.; Park, D.S. New insight and metrics to understand the ontogeny and succession of Lactobacillus plantarum subsp. plantarum and Lactobacillus plantarum subsp. argentoratensis. Sci. Rep. 2018, 8, 6029. [CrossRef]

50. Kim, W.S.; Ren, J.; Dunn, N.W. Differentiation of Lactococcus lactis subspecies lactis and subspecies cremoris strains by their adaptive response to stresses. FEMS Microbiol. Lett. 1999, 171, 57-65. [CrossRef]

51. Srutkova, D.; Schwarzer, M.; Hudcovic, T.; Zakostelska, Z.; Drab, V.; Spanova, A.; Rittich, B.; Kozakova, H.; Schabussova, I. Bifidobacterium longum CCM 7952 promotes epithelial barrier function and prevents acute DSS-induced colitis in strictly strainspecific manner. PLoS ONE 2015, 10, e0134050. [CrossRef] 